\title{
Network Coordinator Perceptions of Early Childhood Community Systems Building and Development Efforts
}

\section{Tuyet-Mai Ha Hoang}

University of Illinois Urbana-Champaign

\section{Brandie Bentley}

University of Illinois Urbana-Champaign

\section{Karen V. Jenkins}

University of Illinois Urbana-Champaign

Crystal Reinhart

University of Illinois Urbana-Champaign

Karen M Tabb ( $\nabla$ ktabb@illinois.edu )

University of Illinois Urbana-Champaign

\section{Research Article}

Keywords: early childhood development, community systems

Posted Date: February 3rd, 2022

DOI: https://doi.org/10.21203/rs.3.rs-1214360/v1

License: (c) (1) This work is licensed under a Creative Commons Attribution 4.0 International License. Read Full License 


\section{Abstract}

Background: Networks for building and developing community systems to support early childhood rely upon volunteer efforts of organization and leadership efforts of coordinators to bring together relevant stakeholders.

Aims: The purpose of this study was to explore the perspectives of network coordinators from 10 different communities in the All Our Kids Early Childhood Networks initiative in and across one Midwestern state.

Methods: We conducted two focus group interviews with 10 participants who worked as network coordinators in public health district offices. A semi-structured focus group interview guide was used to examine community coordinators' perceptions related to lessons learned with community systems development efforts around early childhood outcomes. All interviews were audio recorded and transcribed verbatim. Thematic network analysis was used to analyze all focus group data.

Results: From interviews with network coordinators, three salient themes emerged: (1) strengths of networks to build systems; (2) challenges for coordinators, such as burnout; and (3) the importance of the networks' role within the community.

Conclusions: The study contributes to the existing literature by identifying success and hindering factors that impact the implementation process to sustain long-term impact. The findings can be useful for other ongoing state-supported community-based programs across the US.

\section{Introduction}

Building a community-based systems development program to improve early childhood outcomes is a popular approach to support the well-being of very young children and their families (1). Community systems building is an evidence-supported strategy and adopted widely across different states in the US and in many other countries (2-4), yet building community capacity and implementing meaningful change is a challenging and complex process (5). Community-level and systems change often encounter failures in the areas of implementation and sustained impact (6). In particular, state-based programs lack the flexibility needed to provide the necessary support for high-quality implementation and sustained community-level efforts, because state agencies are designed to manage and monitor grants and programs (time-limited change), as opposed to supporting the development of infrastructure, systems, and mechanisms for implementation (long-term, sustained change) $(5,6)$.

Although the existing literature provides useful frameworks (e.g., the Active Implementation Frameworks or the Able Change Framework) to guide the implementation process aiming for long-term change, the evaluation of a state-supported community-based systems development initiative has been limited to date in the US but can provide understanding of real-life challenges and strengths to achieve sustained impact. More importantly, effective implementation with long-term impact often requires 
interorganizational partnerships as an important strategy for tackling complex public health issues $(7,8)$. In the context of community-based systems development, community organizers and coordinators facilitate connections and collaborations among relevant organizations to improve access to resources and services for the population; thus the role of community organizers/coordinators is crucial to sustain impact. Evaluation based on the perspectives of community organizers is especially needed and has the potential to strengthen long-term community-level changes.

The purpose of this study was to explore the perspectives of network coordinators from 10 different communities in the All Our Kids Early Childhood Networks initiative (AOK Networks) in the state of Illinois. AOK Networks started in 1999 through the collaborative efforts of the Illinois Department of Human Services, Division of Family and Community Services; the Illinois State Board of Education; local health departments, service agencies, and stakeholders. AOK Networks are state-funded community-based systems development initiatives that promote healthy pregnancies, well-being of parents/caregivers, and positive development and growth of children from birth to age five. The AOK Networks are the most comprehensive and long-standing early childhood systems development initiatives in the state of Illinois. AOK Networks' mission focuses on connecting partners and interorganizational relationships across diverse service sectors to address local priorities and develop a coordinated system of services for very young children and their parents or caregivers. Each county has one AOK community coordinator, who recruits, maintains, and facilitates interorganizational partnerships across different sectors, as well as engages parents/caregivers and community stakeholders to create a centralized coordinated system of care for families and very young children.

This study came together as a part of a multi-part evaluation project of the AOK Networks. In this study, a focus group was conducted with AOK community coordinators who were asked to provide their summative evaluations of the strengths and challenges in the implementation process to create system and community-level changes based on the AOK Networks' objectives. AOK coordinators were also asked to evaluate their roles and AOK's roles in their community in supporting the health and well-being of young children and their families. This is one of only a few studies, except for studies outside the US (9), that focus on the perspectives of community coordinators in the implementation process of a statefunded community-based systems development program. The findings can potentially be meaningful for other ongoing state-supported community-based programs across the US and contribute an understanding of real-life challenges in implementing sustained community and system-level changes.

\section{Methods}

\section{Procedure}

Data were collected from all AOK coordinators in Illinois. All study participants signed an informed consent prior to the start of focus group discussion. All study procedures were reviewed and approved by the University of Illinois at Urbana-Champaign Institutional Review Board.

\section{Recruitment and Sample}


Purposive sampling methods were used to recruit and enroll focus group participants. Eligible study participants met the following inclusion criteria: (1) English fluency, (2) currently an AOK Network coordinator. The study consisted of 10 participants representing the 10 AOK Network communities. The study included Illinois counties with diverse geographic characteristics, ranging from very rural to urban communities. Participant demographic characteristics are included in Table 1.

Table 1

Focus Group Participant Demographics from AOK Network Coordinators

\begin{tabular}{|c|c|c|}
\hline Demographic & All participants $n=10$ & $\mathrm{n}(\%)$ \\
\hline \multirow[t]{10}{*}{ Location } & Adams County & $1(10)$ \\
\hline & Chicago Southeast & $1(10)$ \\
\hline & Cicero Township & $1(10)$ \\
\hline & Kane County & $1(10)$ \\
\hline & McLean County & $1(10)$ \\
\hline & Rock Island County & $1(10)$ \\
\hline & Stephenson County & $1(10)$ \\
\hline & Tazewell County & $1(10)$ \\
\hline & Wabash/Edwards Counties & $1(10)$ \\
\hline & Will County & $1(10)$ \\
\hline \multirow[t]{3}{*}{ Race/Ethnicity } & Non-Hispanic/White & $7(70)$ \\
\hline & Hispanic/White & $1(10)$ \\
\hline & Hispanic & $2(20)$ \\
\hline \multirow[t]{4}{*}{ Education Level } & High School (12 years) & \\
\hline & Some College/Technical School (13-15 years) & $2(20)$ \\
\hline & College Graduate (16 years) & $6(60)$ \\
\hline & Graduate School (17 years or more) & $2(20)$ \\
\hline \multicolumn{3}{|l|}{ Age } \\
\hline & 30-39 years & $2(20)$ \\
\hline & $40-49$ years & $2(20)$ \\
\hline & $50+$ years & $6(60)$ \\
\hline
\end{tabular}




\section{Data Collection}

The research and evaluation team conducted two in-person focus group interviews with 10 participants. All focus group interviews were conducted in English. All participants provided written and signed informed consent and permission for the focus group to be audio recorded. Upon completion, all participants received a $\$ 5$ gift card for their engagement.

Three members of the research team who conducted these focus groups were trained focus group facilitators, using a semi-structured interview guide. The focus group interviews lasted 30-60 minutes each in duration, with an average interview time of 46 minutes. Sample questions included, "How is the AOK network perceived in your community?". Whenever possible, an individual note-taker was also present during the focus group sessions to document the discussion. During the focus groups, follow-up questions were asked, as needed, to gain clarity and a deeper understanding of the participants' experiences. Participants were also reminded that they could end their participation at any time during the focus group process without penalty. All study procedures were approved by the University of Illinois Intuitional Review Board.

\section{Data Analysis}

Our team used thematic network analysis to analyze all focus group data (Attride-Stirling, 2001). First, the audio files and field notes were transcribed verbatim. Following transcription, all team members independently reviewed each transcript in full to identify basic codes. The team then met and organized the basic codes into potential categorical themes. The research team independently highlighted themes across the transcripts and met weekly to combine notes and identify common themes across each focus group. Last, the team created a graphic depiction of the thematic network analysis including themes and subthemes. Individual images were compared to reach consensus regarding the final themes. Figure 1 provides a graphic depiction of the thematic analysis.

\section{Results}

The themes and accompanying illustrative quotes can be found in Table 2. A summary of the major findings are described as follows: 
Table 2

Thematic Network Analysis Results with Illustrative Quotes from Qualitative Focus Groups with AOK Network Coordinators $(N=10)$

\begin{tabular}{|c|c|c|}
\hline Theme & Sub-themes & Example Quotes \\
\hline \multirow[t]{4}{*}{ Strengths } & $\begin{array}{l}\text { Passionate, } \\
\text { faithful, and } \\
\text { committed } \\
\text { members }\end{array}$ & $\begin{array}{l}\text { "[My Network is] passionate about helping families and they want our } \\
\text { community to be the best place for families to continue to grow. They } \\
\text { see the potential of what we can do together, it keeps them coming } \\
\text { back." }\end{array}$ \\
\hline & United goal & $\begin{array}{l}\text { "When I go out to meet people to tell them about the network.... I think } \\
\text { they like to share with each other what's going on in their } \\
\text { organization, but also their ultimate goal is children and families and } \\
\text { that's everybody's goal, so we're working towards that together." }\end{array}$ \\
\hline & $\begin{array}{l}\text { Personal and } \\
\text { professional } \\
\text { benefit }\end{array}$ & $\begin{array}{l}\text { "So, I like to be very informative in [my work], just to be ready and } \\
\text { working with clients it's always good to be resourceful that way. I love } \\
\text { what I do and I love visiting my network and getting together with } \\
\text { them and coming up with projects together and all that. It's really } \\
\text { cool." }\end{array}$ \\
\hline & $\begin{array}{l}\text { Real } \\
\text { community- } \\
\text { level impact }\end{array}$ & $\begin{array}{l}\text { "Our collective impact work with getting every single child care center } \\
\text { in our county to utilize the same curriculum, same assessment } \\
\text { process, and now having the school district using the same release } \\
\text { so that we can get all of that information from the school about what } \\
\text { kids participated in what programs, to look at their reading scores } \\
\text { aside that and see are we really having an effect on these specific } \\
\text { children's reading scores by what we're doing with this project. I'm } \\
\text { super proud of that.". }\end{array}$ \\
\hline
\end{tabular}

Strategic "IThe strategic planning process] allows us to show what we've planning accomplished. Here's where we started as an idea in our heads and process $\quad$ put it on paper, but we actually were able to do it, and this is the reason why we did it because we have a good planning process."

Challenges

Coordinator

"In my community, because of the turnaround of the different turnover and burnout coordinators, I just came about this year, I really had to build up the network from scratch."

Bureaucratic obstacles

"Like AOK Connect and the bureaucratic way that the assessment process took place and then here there's more bureaucratic layers at the [local] health department... It's harder to do the same job because there are so many more layers that don't necessarily feel like they're beneficial."

Network recruitment, management, and engagement

AOK's Role within the Community
Identifying needs, connecting people and resources
"My [AOK Network] members straight up last month told me that they just come for guest speakers and were not happy that was not going to be on the agenda every month and that we were actually going to work towards our initiatives. We're currently working on restructuring our meetings and outcomes and working really hard."

"[AOK role is] to determine what the areas of need are and then plan around those areas of need, determine how we're going to either add more services, or change policies, or mindsets, or whatever it is in the community to make whatever changes are need so whatever that issue happens to be addressed." 


\begin{tabular}{|lll|}
\hline Theme & Sub-themes & Example Quotes \\
$\begin{array}{l}\text { Education } \\
\text { and } \\
\text { awareness }\end{array}$ & $\begin{array}{l}\text { "We do a lot of conversations around the local priorities or issues that } \\
\text { are happening in the area and also with AOK we're able to bring } \\
\text { information on the state level so they're not just talking about what's } \\
\text { happening here locally, but we're able to bring in that full picture } \\
\text { which I think other networks or early childhood groups in our area } \\
\text { really don't always have that information." }\end{array}$ \\
$\begin{array}{ll}\text { Voice of } \\
\text { children and } \\
\text { families }\end{array}$ & $\begin{array}{l}\text { "I feel like in our community, I would say also that we're seen as a } \\
\text { collaborative group. That we're passionate about representing kids } \\
\text { and families." }\end{array}$ \\
\hline
\end{tabular}

\section{Strengths}

The first theme to emerged was the strength of the AOK Networks. The benefits gained from AOK Network implementation and participation extended beyond the professional environment, as the participants wholeheartedly believed in AOK's capacity to affect systems-level change as well as create real community-level impact within their local neighborhood and broader communities. AOK Network coordinators endorsed the passionate natures of their network members and praised their dedication to accomplishing the united goal, a significant strength noted across many counties. Having a shared agenda kept all AOK Networks united under a common purpose, and also provided a sense of direction for new and existing members by identifying unique county-level initiatives and goals.

\section{Passionate, Faithful, and Committed Members}

Considering the strengths of AOK Network participation and the implementation process, the coordinators all shared the passion and commitment of their AOK Network members, who represented cross-sector organizations, community organizers, parents, and families. One coordinator stated:

"[My network is] passionate about helping families and they want our community to be the best place for families to continue to grow. They see the potential of what we can do together, it keeps them coming back."

\section{United Goal}

In addition, the coordinators also discussed how their network members have good a understanding of AOK's mission and all work together toward the overarching goal to improve early childhood outcomes:

"When I go out to meet people to tell them about the network....I think they like to share with each other what's going on in their organization, but also their ultimate goal is children and families and that's everybody's goal, so we're working towards that together."

\section{Personal and Professional Benefit}


Many of the AOK coordinators commented on the personal benefit and meaning that they found in their work. Particularly, they discussed how their AOK work aligned with their interests and values, and how it was especially meaningful to them to observe the immediate impact. For example, one coordinator said:

"So, I like to be very informative in [my work], just to be ready and working with clients it's always good to be resourceful that way. I love what I do, and I love visiting my network and getting together with them and coming up with projects together and all that. It's really cool."

Furthermore, the coordinators also identified professional benefits, such as a deep learning curve on the job, where multiple skill sets were required compared to other types of community jobs. The coordinators mentioned the mentality of "sink or swim," but also discussed how much they had learned, ranging from the strategic planning process to relationship building with local organizations and stakeholders. One of the coordinators mentioned:

"I found the skill wheel and there's like 50 parts of that wheel and I was like, that's what it takes to be an AOK coordinator, and I've used that as a tool to say you know what, I'm not so good with this data analytical piece, that's somewhere where I really need to grow. Interpersonal skills got it. I need to learn more."

\section{Real Community-Level Impact}

All of the coordinators described their work as meaningful and "making community impact." Some stated that this was the reason they had applied to be AOK coordinators, because they could work directly with community members and organizations to create real system-level impact and immediate change. One coordinator stated:

"I' $m$ in this because of the community and just helping out one family after the other because you know everything weighs on help and some people need it more than others."

Another coordinator followed up with a comment about community-level impact:

"Our collective impact work with getting every single child care center in our county to utilize the same curriculum, same assessment process, and now having the school district using the same release so that we can get all of that information from the school about what kids participated in what programs, to look at their reading scores aside that and see are we really having an effect on these specific children's reading scores by what we're doing with this project. I'm super proud of that."

\section{Strategic Planning Process}

Although the coordinators discussed difficulties in data collection, assessment, and report generation in the strategic planning process, they also mentioned how going through this process helped them to learn more about applying the framework to execution and implementation. One coordinator stated: 
"[The strategic planning process] allows us to show what we've accomplished. Here's where we started as an idea in our heads and put it on paper, but we actually were able to do it, and this is the reason why we did it because we have a good planning process."

Another coordinator discussed how the strategic plan provided a good resource for their network members and community:

"I like the whole planning process AOK has. Some people don't like the strategic plan, but I like everything that there is to it. ABLE is a good framework at times, so it's a good resource. Just being able to translate that material to the network can sometimes be difficult, but at the same time I feel like I'm educating them, they're learning how the process is going."

\section{Challenges}

The second theme focused on the challenges of the AOK Network coordinators' role in the implementation process. Among common challenges, the coordinators shared some practical obstacles stemming from coordinator turnover and burnout, including a continued need for training, technical support, and organizational assistance. The coordinators discussed the challenges of conducting and following bureaucratic procedures at both the local and state levels, which hindered their community work at times. Last, there was also an identified difficulty in network management, increased recruitment, and engagement of organizations and stakeholders.

\section{Coordinator Turnover and Burnout}

Consistently across all of the AOK counties, the coordinators resonated with the issue of quick turnover and burnout with their jobs. One coordinator mentioned that there was less consistent knowledge passed on from a previous hire to the current coordinator, so they often had to reinvent the wheel:

"In my community, because of the turnaround of the different coordinators, I just came about this year, I really had to build up the network from scratch."

Burnout is another problem for the AOK coordinators because their work can be so demanding in terms of managing both local and state priorities in their network members meetings. One coordinator stated:

"I think that is why the last coordinator left because she catered her meetings to what makes made her members happy and then she tried to do all the work by herself and she burnt herself out."

\section{Bureaucratic Obstacles}

The coordinators talked about how the strategic planning process was a strength, yet the steps needed to complete assessment and reporting often presented as bureaucratic obstacles. One coordinator described this process: 
"So, out of the five days in a week, three of them were on paperwork and whatnot, pulling me out of the community...[My community partners] are feeling the state is pulling us instead...it coming from the local community."

Additional comments indicated that bureaucratic barriers happen when state-level priorities increase the coordinators' burden of work when they are implemented at the local level. One coordinator stated:

"Like AOK Connect and the bureaucratic way that the assessment process took place and then here there's more bureaucratic layers at the [local] health department...It's harder to do the same job because there are so many more layers that don't necessarily feel like they're beneficial."

\section{Network Recruitment, Management, and Engagement}

Another major challenge for coordinators were issues related to network recruitment, management, and engagement. Within this theme, the coordinators talked about a consistent need to increase representation of diverse cross-sector organizations and parents' voices. As one coordinator said:

"There are always things we can do to improve. There's always partners still missing from the table that we need to get engaged. There are always opportunities to gain more community support. We definitely need more parental input into the programs and services, I think that's a statewide issue. So, I think that's something that we definitely could work toward."

Although the coordinators recognized the need for recruitment, they also described the difficulties of managing their current networks and engaging their current members in a way that was beneficial for the AOK initiatives while maintaining interest from their cross-sector partners. This finding highlighted the challenges of coordinators' job in balancing different parties' interests and trying to improve local collaboration for successful implementation of state-level initiatives. A coordinator described this challenge:

"My [AOK Network] members straight up last month told me that they just come for guest speakers and were not happy that was not going to be on the agenda every month and that we were actually going to work towards our initiatives. We're currently working on restructuring our meetings and outcomes and working really hard."

\section{AOK's Role within the Community}

The last theme was coordinators' perceptions of AOK's role within their communities. Participants describe AOK as the "voice of children and families," as they work to educate the community about crucial early childhood issues. Through its efforts, AOK connects people to resources and promotes the importance of establishing positive health outcomes during early childhood.

\section{Identifying Needs, Connecting People and Resources}


All of the coordinators agreed that AOK's role was to identify needs and connect people and resources at the community level to address issues related to early childhood development. For example, one coordinator said, "if we can't get things done, we're going to connect you to the person who can...AOK has the answers." This theme was consistent across all counties. Another coordinator provided an additional explanation:

"[AOK's role is] to determine what the areas of need are and then plan around those areas of need, determine how we're going to either add more services, or change policies, or mindsets, or whatever it is in the community to make whatever changes are need so whatever that issue happens to be gets addressed."

\section{Education and Awareness}

Another important role that AOK Networks had was to bring information and awareness about state and local issues to their community organizations and members. This was important for communities where access to accurate information was difficult. One coordinator stated:

"We do a lot of conversations around the local priorities or issues that are happening in the area and also with AOK we're able to bring information on the state level so they're not just talking about what's happening here locally, but we're able to bring in that full picture which I think other networks or early childhood groups in our area really don't always have that information."

\section{Voice of Children and Families}

Last, all of the AOK coordinators agreed that AOK was seen as a voice for families and children and an advocate for their needs. One coordinator said:

"I think in the Human Service field AOK is perceived as a voice of families with young kids."

The coordinators often stated that they were drawn to this work because they were also passionate about improving early childhood outcomes and the well-being of families and young children in their communities. For example, one coordinator said: "I feel like in our community, I would say also that we're seen as a collaborative group. That we're passionate about representing kids and families."

\section{Discussion}

Community-based systems development based on the collaboration of cross-sector organizations is an evidence-based approach to tackling important public health issues, such as enhancing early childhood outcomes $(1,10)$. Since 1999, the AOK Networks in Illinois have included 10 counties, where coordinators work with local public health districts to establish cross-sector provider networks that support community engagement, family support, and system building to improve early childhood outcomes in their local area. However, state-based programs often face implementation challenges in maintaining long-term impact and system-level changes (5). Furthermore, succeeding in systems development requires extensive state- 
to-local support, and coordinators play a key role in the success of the local AOK Networks. This study explored the AOK community coordinators' perceptions of state-funded community-based programs for early childhood development in maintaining long-term impact. Overall, the AOK coordinators indicated strong positive support for AOK Networks' role within their communities. And similar to other evaluation studies in early child development, the community coordinators indicated both strengths and challenges in the process of implementing local and system-level changes (10). One implication of the study is to discuss how to better support coordinators in their critical role.

Early childhood is a significant period in human development where protective factors are established to extend across the life course. The AOK coordinators described the importance of AOK Networks' role within their communities, especially in being "a voice of families with young kids" to advocate for resources and support services as well as to bridge knowledge gaps between local and state priorities. In order to achieve this, the coordinators emphasized the importance of AOK Network activities on identifying needs in their communities, committing to strategic planning around those needs, centralizing resources, and connecting cross-sector providers. With the goal of ensuring healthy and positive outcomes for very young children and their families, AOK Networks also provide infrastructure to increase access to services and awareness of local and state-level early childhood support. The coordinators' responses indicate the importance of state-funded community-based programs in building state-to-local support and maintaining cross-sector provider networks to improve early childhood outcomes.

The AOK coordinators highlighted multiple strengths of being a part of the AOK Networks and implementation process. They discussed having passionate and committed cross-sector partners and organizations, who stand with the AOK Networks in working toward the goal of ensuring and improving the well-being of very young children and their families. Regarding the implementation process of state initiatives, AOK coordinators described it as a meaningful path for their professional and personal development, where they learned a great deal through the strategic planning and maintaining of crosssector provider networks. The coordinators discussed the personal satisfaction they felt in seeing community-level changes and real-life impacts that directly resulted from their work at AOK. The experiences of the coordinators reflect the amount of dedication and personal motivation needed for AOK work, as the coordinators all recognized how difficult their role was and the demanding skill set that they needed to succeed. The contribution of community coordinators is crucial for state-funded programs such as AOK Networks because of the level of facilitation, engagement, and development of state-to-local structures and local-to-local connections to ensure sustained community-level impact.

AOK coordinators play an important role in the success and long-term impact of state-funded programs, and the challenges that come with this role are evident in the coordinators' experiences. The coordinators described three main areas where challenges come up: network management, bureaucratic obstacles, and turnover/burnout. Some of the difficulties related to network management included recruiting and increasing representation of different cross-sector agencies. This process required additional communitylevel connections and relationship building on the coordinator's part while also trying to maintain the engagement of existing partners. Coordinators also discussed the challenge of balancing state-level 
priorities with the interests/buy-in of local community organizations toward a cohesive overarching goal. A similar challenge has been discussed in another evaluation study of community-based projects to address interpersonal violence in Canada (9). There were gaps in terms of needs and urgency between state and local priorities and the coordinators' job to be a voice bridging those differences. The coordinators discussed that this process could be very difficult, especially when they had to follow the many bureaucratic steps required by state-prioritized outcomes (such as in the strategic planning process), while establishing and maintaining a local infrastructure to address immediate needs in their community. Some coordinators mentioned the issue of burnout and high turnover rate because AOK work required a large skill set and a level of commitment that many coordinators struggled to maintain.

To implement and maintain impact in early childhood systems development requires extensive state-tolocal support, and state oversight can help to ensure quality and consistency across sites. This includes not only the supports the state provides to the local AOK Networks, but also considers the potential obstacles in the implementation process and begins to define the long-term goal of AOK rather than timelimited objectives. Building state-level implementation support for AOK coordinators helps to promote effective partnering with local communities for sustained impact. Coordinators play a key role in the success of the local AOK Networks, so support for coordinators' work with special attention to unique challenges in each network may address the issue of burnout and turnover. Therefore, more fully understanding this role and what each local coordinator brings to the role is essential to understand the success of the local networks. We recommend developing a project coordinator questionnaire. The project coordinator questionnaire would assess each coordinator's skills, background, work style, perceived roles, perceived challenges, and accomplishments. This information can be linked to other data sources so that we can understand the relationship between what the coordinator does, how the state can support the coordinator, the overall effectiveness of the local network, and the program's outcomes.

Successful implementation and sustained impact of early childhood systems development requires a significant amount of state-to-local support. Providing ongoing, differentiated technical assistance, training, and support to local AOK Networks and their coordinators is important for long-term success. Topics may include strategic planning, using data for program improvement at the state and local levels, data collection approaches, recruitment, and engagement strategies with local organizations. Technical assistance for state AOK coordinators might address how to use local AOK data and reports to understand the training and technical assistance needs of coordinators, collect data on health trends, and ascertain the effectiveness of any implemented local initiatives, which can be used to advocate for AOK at the state and national levels - that is, to make a case for the value and impact of the AOK Networks. Training and support can also be provided through peer-to-peer networks. Such networks create opportunities for local communities to share success stories and innovations across the state. This may be accomplished through quarterly networking meetings at which such sharing is the primary focus, separate from training.

\section{Limitations}


Our study has several noted limitations. Although our sample of AOK coordinators were from diverse geographic locations in Illinois ranging from rural to urban settings, the sample size was relatively small $(N=10)$. Furthermore, the evaluation focused on community-based early childhood development programming, so the identified challenges might be unique to the population of children from birth to age five and their families or caregivers. Last, we mainly discussed issues related to the implementation and maintenance of early childhood development programs for long-term impact based on the coordinators' perspectives. The evaluation process should include perspectives from more than just community coordinators and may benefit from the perspectives of state agencies, parents, and families in local communities.

\section{Conclusion}

Community-based early childhood systems development is a widely adopted and evidence-based approach to addressing health disparities. The state of Illinois has been a leader in these initiatives to prioritize the well-being of families and very young children. This study captured the perspectives of community coordinators in the implementation process of a state-funded community-based systems development program. The study contributes to the existing literature by identifying the successes and hindering factors that impact the implementation process to sustain long-term impact. These findings can be useful for other ongoing state-supported community-based programs across the US.

\section{Declarations}

\section{a. Ethics approval and consent to participate.}

The study was reviewed and approved by the University of Illinois Institutional Review Board (IRB). All methods were carried out in accordance with relevant guidelines and regulations to protect human subjects outlined by the University of Illinois IRB. All participants provided informed consent.

b. Consent for publication - Not applicable.

c. Availability of data and materials

The datasets generated and/or analyzed during the current study are publicly available and can be found using the following link: https://www.openicpsr.org/openicpsr/project/161001/version/V1/view

d. Competing interests - none.

e. Funding - University of Illinois Research Incentive Program Grant awarded to KT.

f. Authors' contributions - KT designed the study, collected and analyzed data, reviewed, and edited final draft. MH wrote first draft and analyzed data. BB collected and analyzed data, reviewed, and edited final draft. CR collected and analyzed data, reviewed, and edited final draft. KJ reviewed and edited final draft. 
g. Acknowledgments - All authors would like to thank the participants of the study.

\section{References}

1. Dinnebeil LA, Mclnerney W, Fox C, Juchartz-Pendry K. An analysis of the perceptions and characteristics of childcare personnel regarding inclusion of young children with special needs in community-based programs. Topics in Early Childhood Special Education. 1998;18(2):118-28.

2. Gerlach AJ, Browne AJ, Greenwood M. Engaging Indigenous families in a community-based Indigenous early childhood programme in British Columbia, Canada: A cultural safety perspective. Health \& Social Care in the Community. 2017;25(6):1763-73.

3. Neuman MJ, McConnell C, Kholowa F. From early childhood development policy to sustainability: the fragility of community-based childcare services in Malawi. International Journal of Early Childhood. 2014;46(1):81-99.

4. Zhou S, Zhao C, Huang X, Li Z, Ye R, Shi H, et al. The effect of a community-based, integrated and nurturing care intervention on early childhood development in rural China. Public Health. 2019;167:125-35.

5. Van Dyke MK, Naoom SF. The critical role of state agencies in the age of evidence-based approaches: The challenge of new expectations. Journal of Evidence-Informed Social Work. 2016;13(1):45-58.

6. Foster-Fishman PG, Watson ER. The ABLe change framework: a conceptual and methodological tool for promoting systems change. American Journal of Community Psychology. 2012;49(3-4):503-16.

7. Yessis J, Riley B, Stockton L, Brodovsky S, Von Sychowski S. Interorganizational relationships in the Heart and Stroke Foundation's Spark Together for Healthy Kids ${ }^{\text {TM}}$ : insights from using network analysis. Health Education \& Behavior. 2013;40(1_suppl):43S-50S.

8. Agonafer EP, Carson SL, Nunez V, Poole K, Hong CS, Morales M, et al. Community-based organizations' perspectives on improving health and social service integration. BMC Public Health. 2021;21(1):452.

9. Singh CD, Andrews NCZ, Motz M, Pepler DJ, Leslie M, Zuberi S. Trauma-informed and relational approaches to service provision: building community-based project capacity to respond to interpersonal violence through a national initiative. BMC Public Health. 2020;20(1):1833-.

10. Partain PI, Kumbamu A, Asiedu GB, Cristiani V, Deling M, Weis C, et al. Evaluation of community programs for early childhood development: parental perspectives and recommendations. Maternal and Child Health Journal. 2019;23(1):120-30.

\section{Figures}




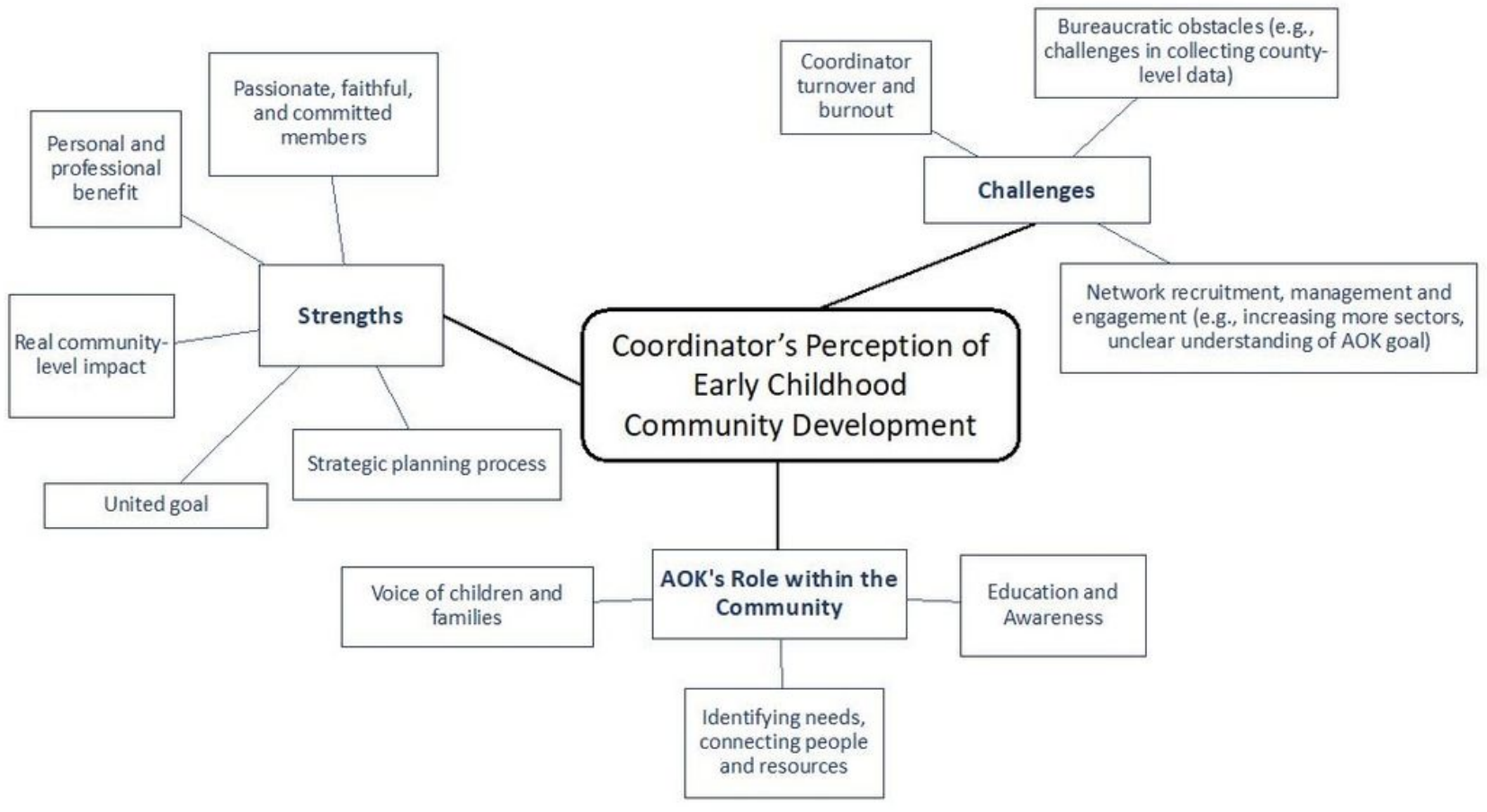

Figure 1. Thematic Network Analysis of Coordinator's Perception

\section{Figure 1}

See image above for figure legend. 